\title{
A NEW PERSPECTIVE ON THE ISSUE OF PRIVACY: COVID-19 PANDEMIC VS PRIVACY
}

\author{
Adewale Adegoroye, Marc Conrad ${ }^{1}$ and Xiaohua Feng ${ }^{1}$ \\ School of Computer Science and Technology, University of Bedfordshire \\ Luton, United Kingdom \\ ${ }^{l} \mathrm{Dr}$.
}

\begin{abstract}
The current COVID-19 experience seems to expose the need for a new approach about how we interpret and handle privacy. This paper investigates the notion of privacy whether it is old, current, or simply misunderstood. The use of technologies is limited by a shortage of data, and by too many data that cannot be accessed due to privacy rights. The authors present the limitations, constraints, and pitfalls that privacy could pose on the use of AI and emerging technology as a potential nonpharmaceutical weapon against the current and future pandemic. Addressing these restrictions would require careful balancing among data protection, economy and public health, and robust engagement between human and digital world. This paper seeks to encourage governments, decision-makers and developers to rethink their perspective of user privacy.
\end{abstract}

\section{KEYWORDS}

COVID-19, Data Protection, Privacy, GDPR (General Data Protection Regulation)

\section{INTRODUCTION}

We often look quizzical on privacy whenever we speak of addressing crime, terrorism, even corruption issues with digital technology. As of August 28, 2020, the COVID-19 coronavirus had affected 213 countries and territories across the world, infecting more than 28.5 million people and causing more than 840,000 deaths and counting since the first case in December 2019 (Worldometers, 2020). Thus, posing an unprecedented economic and social challenge to the citizens, businesses, and government worldwide. In response to this global challenge, social distancing, contact tracing app, location tracking app, and digital surveillance are among the proposed nonpharmaceutical interventions to delay and/or reduce the spread of this virus. Thus, opening yet another critical question on how to balance the privacy challenges of these technologies with eradicating that which threatens our health and economy - the public and the government alike. How should privacy be handled during a pandemic? Which is more important, the country's economy: citizens' privacy or their safety? To date, there has not been an easy way of addressing any of these questions. The notion of using location history data, for example, to trace the COVID-19 coronavirus spread is among the new ethical and security concerns raised about privacy. This implies infectious people who might not know, either because they have not yet developed symptoms, or because their symptoms are mild will be identified, monitored, and supported where possible. With the use of this list, it would be possible to find any other smartphone (or smartphone user) that was close to the phone at that time (Fair, 2020). In the following, this paper seeks to examine the concept of privacy from a different point of view during the pandemic.

\section{THE CONCEPTS OF PRIVACY AND THE COVID-19 PANDEMIC}

In 1967, Alan Westin identifies privacy from two unique points of view, in basic context and the socio-environment. In basic context, he defines privacy as the right of people, associations or organisations to decide for themselves where, how and to what degree knowledge about them is transmitted to others (Westin, cited in; Margulis, 2003). With social engagement, Westin defines privacy as the voluntary and temporary 
isolation of an individual from the wider public by physical or psychological means, either in the state of isolation or in the intimacy of a small group or a situation of anonymity or reservation by large groups (Margulis, 2003). Altman 1975 cited in; Margulis (2003) argue that when a person regulates their social interaction, he/she gets privacy and therefore defined it as "the selective control of access to the self". Over the years, there had been several debates on the interpretations of privacy among scholars and business leaders. Several studies (e.g. Bennett, 1992; Solove, 2007; Gutwirth, 2002) argue that efforts to define the concept of privacy have proven to be famously challenging, complex and outside the reach of just about any scholar exploring it. Furthermore, Fuchs (2011) believes that privacy is valuable to firms and affluent people in the economic sense, as it conceals wealth disparity; yet it is also exploited by the very same industries who tend to manipulate employees and/or customers. Nissenbaum (2004) states that it is not the sharing of information that is a problem, but the gathering, exchange and exploitation of it outside the right mutually agreed with social boundary. However, with the rise of new digital technology and AI, a further consensus has been reached on understanding that privacy occupies several dimensions: (1) Privacy of the person; (2) Privacy of behaviour and action; (3) Privacy of communication; (4) Privacy of data and image; (5) Privacy of thoughts and feelings (6) Privacy of location and space (7) Privacy of association (Finn, Wright and Friedewald, 2013).

One of the COVID-19 pandemic's implications is working from home. Zoom, Hangout Meets, Houseparty are among the top video conferencing software adopted as an essential productivity tool during this period (Sydow, 2020); even the British Prime Minister Boris Johnson also claimed to use Zoom for his cabinet meetings (BBC, 2020). Reports suggested that while there was no evidence of Zoom selling user data to third parties of any sort, the terms of use of the company offer a lot of leeways to collect and exchange information. Its instant messages among others can be used to promote advertising campaigns (O'Flaherty, 2020). The hosts could turn on 'attention monitoring' to test whether the audience is paying attention during the call (O'Flaherty, 2020). While Zoom may meet the United State privacy standards, it is believed that it does not meet the European Union's GDPR standards (European Parliament and EU Council, 2018).

On 23 March 2020, the EU Commission called on European mobile network operators to provide anonymised and aggregated data to the Commission to track the spread of viruses and to identify priority areas for medical supplies (Mark Scott, Laurens Cerulus and Laura Kayali, 2020). Another example, all mobile service providers in Australia are expected to retain onto their network, two years of data relating to the usage of each smartphone, including location information for the customer. It complies with the Australian Telecommunications Act 1997, which requires federal, state and local governments to request access for purposes such as law enforcement, national security, and public revenue safety (Australian Government, 2020). Fair (2020) did argue against this. He explained that even though a pandemic is arguably a threat to national security, being infected with COVID-19 is not a crime. However, while it is not expressly referred to in the Australian Legislative Act, 2020, the Act requires the Federal Health Minister to take whatever action is required to prevent or monitor the "emergence, establishment or dissemination" of the declared emergency disease (Australian Legislative Act, 2020). Like several others, the Government of Australia faces a crisis that is more severe in order of magnitude. Studies suggest citizen trust in the public administration and giant tech companies may have been reduced due to events such as revealed by lawsuits against Facebook, Zoom and the disclosure of classified information or government surveillance of her people as reported by Edward Snowden in 2013 (MacAskill et al., 2013; Belot, 2018; Coyne, 2019). Nonetheless, others around the world, such as the Australians, are believed to be non-hesitant to see their private data used in this manner if it means saving lives, reduces the economic challenges, and put a stop to the spread of the virus.

So far, the latest COVID-19 surveillance metrics indicate that, relative to April and May 2020, the number of new COVID-19 cases per day in the UK has dramatically decreased at the national level as of August 2020 (Public Health England and NHSX, 2020). There is, to date, minimal or inadequate scholarly analysis and evidence to show whether these changes witnessed in the daily rate of new COVID-19 case are subject to the users' willingness to compromise their privacy with the AI and digital technology solution. 


\section{AI VS PRIVACY VS COVID-19: LIMITATIONS, CONSTRAINTS AND PITFALLS}

Naudé (2020) examines AI as a method for monitoring and forecasting, AI as a method for diagnosis and prognosis, AI for medications and vaccination, and social regulation in the battle against the pandemic; and acknowledged limits, restrictions, and risks. The result indicates that data is vital for the effective use of AI against the pandemic, while voicing fear that public health issues may outweigh data protection issues and that mission creep may arise, with governments maintaining their citizens' excessive monitoring long after the pandemic has ended. Kapa, Halamka and Raskar (2020) indicate that further research is needed as to whether privacy-enabled measures minimise the effectiveness of contact tracing due to reliance on private consumer response rather than strict implementation by a central authority. The current study shows that with the potential of emerging epidemic control technologies, the possible advantage of combating existing pandemic threats or future outbreaks cannot be overlooked (Kapa, Halamka and Raskar, 2020). Oliver et al. (2020) conducted a COVID-19 related survey involving 156,614 general adult population (over 18) via social media posts to assess the Spanish citizens' situation and perception on their social contact behaviour during the confinement, their economic impact, their work environment situation and their health status. The study indicates that Spaniards have shown high conformity with all confinement measures, although more than a quarter of the population reports lacking the necessary means to self-isolate. The survey results revealed gender and age matter regarding social interaction behaviour, the economic and labour impact, and the ability to self-isolate. This takes us back to discussing the usage of applications such as the COVID-19 Exposure Notification System. Sakul-Ung and Smanchat (2019) 's Integrated Privacy System study revealed that the framework includes helpful components for data protection management, development and monitoring mechanisms. This may be useful in developing privacy-aware AI products and/or services. Nanni et al., (2020) advocate the significant benefit of a decentralised approach where contact and location data are strictly gathered to be shared (separately, selective and voluntarily) only when the person tested positive while the individual has full control of his/her privacy. They recommend that:

- existing decentralized architectures be extended carefully to manage the collection of location data locally on user's device, and allow the user to share with health authorities, for instance as they deem fit and for a specific aim.

- a long-term effort to create the concept of a Personal Data Store that allows users to contribute to collective good as they wish.

\section{CONCLUSION}

From the $10^{\text {th }}$ of April 2020, positive study figures include positive case outcomes from the swab test. But there are limited data or studies to suggest whether this is in relations to the AI and digital intervention; neither can we proof "How" nor at what rate. (Kelly, Kerr and Drennan, 2017) Findings show that while customers tend to have faith in social network sites (SNSs) to protect their private information, they are hesitant to support ads or products on such pages. Over time, the users' autonomy, connectedness and competence do change from experimenters who had little to lose to acceptors who felt their social life was more important than their privacy concerns to administrators who monitored their information strategically to reduce their exposure. Its seems evident that while the concept of privacy may not have changed, it has broadened as a result of emerging digital technologies and data consumption. It implies the notion of what constitutes 'privacy' in particular for digital service providers might need to change or at least be underpinned differently. Although the link between these non-pharmaceutical interventions and the fight against COVID-19 is lacking in evidence, there is a need for a further empirical study on the new perspective on the concept of privacy. We also recommend further study on how to measure the relationship between user privacy acceptance and AI concerning issues such as a pandemic. 


\section{REFERENCES}

Australian Legislative Act (2020): Telecommunication and Biosecurity Art. https://www.legislation.gov.au/.

BBC (2020) Coronavirus: Zoom under increased scrutiny as popularity soars. https://www.bbc.co.uk/news/business52115434 (Accessed: May 26, 2020).

Belot, h. (2018) Security leak about spy agency referred to AFP. https://www.abc.net.au/news/2018-04-29/labor-blamesgovernment-for-security-leak/9708594

Bennett, C.J. (1992) Regulating privacy: data protection and public policy in Europe and the United States.

Coyne, H. (2019) 'The Untold Story of Edward Snowden's Impact on the GDPR', The Cyber Defense Review, 4(2), pp. 65-80. doi: 10.2307/26843893.

European Parliament and EU Council (2018) General Data Protection Regulation (GDPR) - Official Legal Text. https://gdpr-info.eu/ (Accessed: Aug 28, 2020).

Fair, P. (2020) 'Privacy vs pandemic: government tracking of mobile phones could be a potent weapon against COVID-19', The Conversation, Khan, Stephen

Finn, R.L., Wright, D. and Friedewald, M. (2013) 'European Data Protection: Coming of Age: Seven types of privacy'. Springer, Dordrecht

Fuchs, C. (2011) 'Towards an alternative concept of privacy', Journal of Information, Communication and Ethics in Society, 9(4), pp. 220-237. doi: 10.1108/14779961111191039.

Gutwirth, S. (2002) Privacy and the information age. Lanham, Md [u.a.]: Rowman \& Littlefield.

Kapa, S., Halamka, J. and Raskar, R. (2020) 'Contact Tracing to Manage COVID-19 Spread-Balancing Personal Privacy and Public Health', Mayo Clinic Proceedings, 95(7), pp. 1320-1322. DOI: 10.1016/j.mayocp.2020.04.031.

Kelly, L., Kerr, G. and Drennan, J. (2017) 'Privacy concerns on social networking sites: a longitudinal study', Journal of Marketing Management, 33(17-18), pp. 1465-1489. doi: 10.1080/0267257X.2017.1400994.

Lee, H., Park, H. and Kim, J. (2013) 'Why do people share their context information on Social Network Services? A qualitative study and an experimental study on users' behavior of balancing perceived benefit and risk', International Journal of Human-Computer Studies, 71(9), pp. 862-877. doi: 10.1016/j.ijhcs.2013.01.005.

MacAskill, E., Dance, G., Cage, F., Chen, G. and Popovich, N. (2013) NSA files decoded: Edward Snowden's surveillance revelations explained. http://www.theguardian.com/world/interactive/2013/nov/01/snowden-nsa-filessurveillance-revelations-decoded (Accessed: Jun 2, 2020).

Margulis, S.T. (2003) 'On the Status and Contribution of Westin's and Altman's Theories of Privacy', Journal of Social Issues, 59(2), pp. 411-429. doi: 10.1111/1540-4560.00071.

Mark Scott, Laurens Cerulus and Laura Kayali. (2020) 'European Commission tells carriers to hand over mobile data in coronavirus fight', Politico, U.S. edition.

Nanni, M., Andrienko, G., Barabàsi, A.-., Boldrini, C., Bonchi, F., Cattuto, C., Chiaromonte, F., Comandé, G., Conti, M., Coté, M., Dignum, F., Dignum, V., Domingo-Ferrer, J., Ferragina, P., Giannotti, F., Guidotti, R., Helbing, D., Kaski, K., Kertesz, J., Lehmann, S., Lepri, B., Lukowicz, P., Matwin, S., Jiménez, D., Monreale, A., Morik, K., Oliver, N., Passarella, A., Passerini, A., Pedreschi, D., Pentland, A., Pianesi, F., Pratesi, F., Rinzivillo, S., Ruggieri, S., Siebes, A., Torra, V., Trasarti, R., Van Den Hoven, J. and Vespignani, A. (2020) 'Give more data, awareness and control to individual citizens, and they will help COVID-19 containment', Transactions on Data Privacy, 13(1), pp. 61-66.

Naudé, W. (2020) 'Artificial intelligence vs COVID-19: limitations, constraints and pitfalls', AI \& SOCIETY. doi: 10.1007/s00146-020-00978-0.

Nissenbaum, H. (2004) 'Privacy as contextual integrity', Washington Law Review, 79(1), pp. 119-157.

O'Flaherty, K. (2020) 'Zoom 's A Lifeline During COVID-19: This Is Why It's Also A Privacy Risk'

Oliver, N., Barber, X., Roomp, K. and Roomp, K. (2020) 'The Covid19Impact Survey: Assessing the Pulse of the COVID-19 Pandemic in Spain via 24 questions', Computers and Society.

Public Health England and NHSX (2020) 'Coronavirus (COVID-19) in the UK: Daily cases by specimen date, by nation' https://coronavirus-staging.data.gov.uk/ Last Accessed: August 28,2020.

Sakul-Ung, P. and Smanchat, S. (Dec 2019) Towards Privacy Framework in Software Development Projects and Applications: An Integrated Framework. IEEE, pp. 1.

Solove, Daniel J (2007) '"I've Got Nothing to Hide" and Other Misunderstandings of Privacy', The San Diego law review, 44(4), pp. 745.

Sydow, L. (2020) Video Conferencing Apps Surge from Coronavirus Impact | App Annie Blog. Available at: https://www.appannie.com/en/insights/market-data/video-conferencing-apps-surge-coronavirus/ (Aug 28, 2020).

Worldometers Coronavirus Update (Live): https://www.worldometers.info/coronavirus/ (Accessed: Aug 28, 2020). 